\title{
Study on Open Practice Teaching System of Innovation-oriented IOT Engineering
}

\author{
Xiao-hua Li \\ School of Electronic Information Engineering \\ Foshan University \\ Foshan China
}

\author{
Qiu-ming Lin \\ School of Electronic Information Engineering \\ Foshan University \\ Foshan China
}

\begin{abstract}
Facing the immature situation of the practice teaching system of IOT engineering in Colleges and Universities, The subject of this study is to propose a practice teaching system to perfect the current IOT engineering talent training mode to meet market demand. On the basis of analyzing the problems existing in the practical ability training and the industry consensus of the technology and course system, we designed and implemented an open practice teaching system of innovationoriented IOT engineering. The system consists of two types of roles and four modules. Our practice shows that the system can guarantee the efficient management of practice teaching, makes students and teachers pay more attention to how to improve the efficiency of realization of students' practical ability, and can effectively meet the individual needs of students to improve the learning initiative. It needs to be emphasized that this practice teaching system is a dynamic system, and it needs to adjust the corresponding modules with the changes of technical system and market demand.
\end{abstract}

Keywords_colleges and universities; IOT engineering; practice teaching system; open

\section{INTRODUCTION}

The Internet of Things (IOT) is another wave of information industry after computer, Internet and mobile communication [1]. The growing demand for IOT engineering talent has prompted domestic colleges and universities to set up IOT engineering since 2010 in China. The IOT engineering is a typical multi-disciplinary integration professional. Colleges and universities have not reached a consensus on the IOT engineering talent training system. The construction of talent training system of IOT engineering is now at the stage of learning from each other and exploratory, especially in Practice Teaching System (PTS) of IOT engineering, there are still many problems. So it has the reality urgency to study and construct of a PTS of innovation-oriented IOT engineering, which can improve the students' learning initiative and cultivate talents to meet the needs of IOT innovation [2].

\section{ANALYSIS OF PROBLEMS EXISTING IN PRACTICAL TEACHING SYSTEM OF IOT ENGINEERING}

At present, there are still many problems in the PTS of IOT engineering in colleges and universities. Mainly include:
- The direction of talent cultivation has not yet reached a consensus. Since IOT engineering is closely related to the Internet, mobile communications networks and sensor networks, there is still no consensus on the directions of talent cultivation in IOT engineering.

- The systematic PTS has not yet been formed. The IOT engineering PTS in most colleges and universities is based on the simple clipping of the practice teaching courses of related majors, which leads to the fragmentation of PTS.

- The content of the practice course is simple and casual. On one hand, experiments mainly carry on the verification operation, lack design and innovative experiment; On the other hand, the content practice is mainly by teacher's subjective will, rather than students' ability, students' personal interest and market demand for talents, to decide what students need to learn.

- $\quad$ "Double qualified" teachers are insufficient. In colleges and universities, there are not enough teachers who have both theoretical knowledge and practical experience.

- Practical teaching infrastructure is incomplete. Internet of things engineering as a new major, it's the construction of laboratory is still in its infancy, it has not yet been established enough off-campus practice teaching base, all of these restrict the cultivation of the students' practical ability.

- There is no scientific and systematic quality evaluation standard in practice teaching sections.

\section{DESIGN OF OPEN PRACTICE TEACHING SYSTEM OF INNOVATION-ORIENTED IOT ENGINEERING}

It is an effective way to get rid of the problems of practice teaching of IOT engineering to build up an opening PTS aiming at the cultivation of innovative practice ability. The implementation of this PTS can cultivate students into qualified IOT engineering talents, as shown figure 1. 


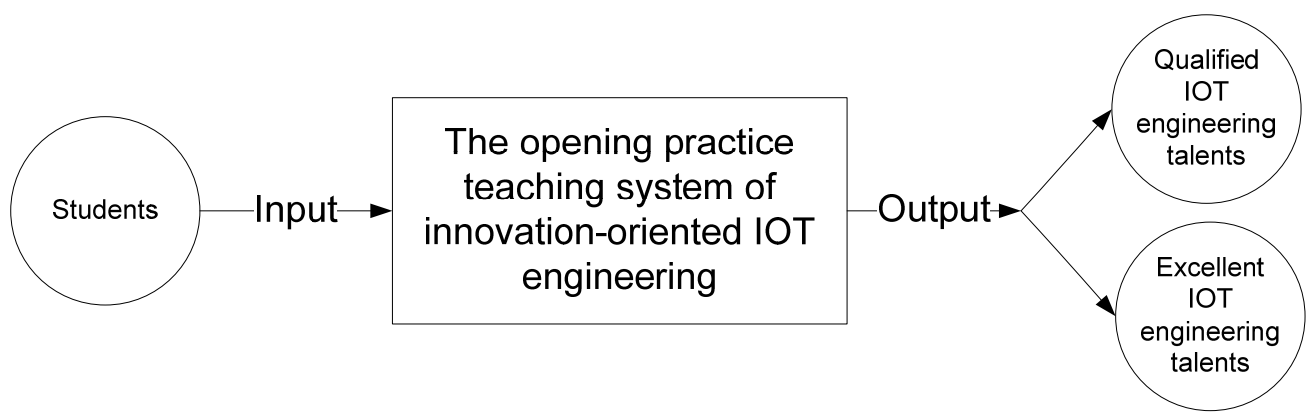

Fig. 1. The implementation effect of the practice teaching system

TABLE I.

TECHNOLOGY AND COURSE SYSTEM OF IOT ENGINEERING

\begin{tabular}{|c|c|c|}
\hline Technology level & Technical structure & Course \\
\hline \multirow{3}{*}{ Application layer } & Internet of things applications & Industry application development, Robot, wearable devices \\
\hline & Internet of things security & $\begin{array}{l}\text { Wireless sensor network communication encryption, Gateway encryption and validation, Data } \\
\text { security }\end{array}$ \\
\hline & IOT cloud computing & $\begin{array}{l}\text { Application development of IOT cloud computing, Data center technology, Virtualization } \\
\text { technology, Cloud computing client development }\end{array}$ \\
\hline \multirow{5}{*}{ Network layer } & Database & Database programming, Database security \\
\hline & IOT middleware & Web Service development, IOT standardization, Standardized hardware development \\
\hline & Mobile Internet & $\begin{array}{l}\text { Mobile device hardware development, Embedded programming, Mobile Internet application } \\
\text { development }\end{array}$ \\
\hline & Internet & LAN technology, Industrial Ethernet, Web server, Network programming \\
\hline & The mobile communication & $\begin{array}{l}\text { GPRS communication, 3G / 4G communications and data transmission, Wireless } \\
\text { communication module development }\end{array}$ \\
\hline \multirow{9}{*}{ Perception layer } & IPv6 technology & ipv6 protocol, IPv6-IPv4 gateway \\
\hline & The Wi-Fi technology & Wi-Fi node design, Wi-Fi embedded programming, TCP/IP protocol \\
\hline & IOT gateway & $\begin{array}{l}\text { Embedded gateway design, Android/iOS embedded development, IPv6 gateway technology, } \\
\text { Embedded gateway design }\end{array}$ \\
\hline & Wireless sensor network & ZigBee/IPv6 / Wi-Fi wireless sensor network \\
\hline & ZigBee technology & Tiny OS operating system \\
\hline & RFID technology & RFID principle, RFID frequency band and ISO instructions, RFID tags, Barcode technology \\
\hline & Sensor technology & $\begin{array}{l}\text { Common sensor principle, Data acquisition and data processing, GPS positioning, Image and } \\
\text { sound collection and processing }\end{array}$ \\
\hline & Actuator technique & Motor driven control, Relay drive control, Alarm driver control, Solenoid valve control \\
\hline & Microprocessor technology & $\begin{array}{l}\text { Single-chip microcomputer and interface technology, } \mu \mathrm{Cos} / \text { Linux embedded system, Single } \\
\text { chip microcomputer development }\end{array}$ \\
\hline
\end{tabular}

A. Analysis of technology and course system of IOT engineering

Through the analysis of the general consensus of the industry, the technology and course system of IOT engineering can be summarized as shown in table 1 [5].

\section{B. The framework of practice teaching system}

The framework of the IOT engineering PTS designed in this paper is shown in figure 2. The practice teaching system consists of 2 types of roles and 4 modules to form a structured organism, which is effectively coordinated and operated under the drive of cultivating students' practical ability. The two types of roles are students and system service providers, the system service providers include the teaching management organization and teachers [4]. The four modules are: practical ability module, practical ability support module, practical ability realization module, and practical ability evaluation module.

\section{1) The practical ability module}

The basic functions of the practical ability system include: defining the hierarchical structure of professional practice ability [3], and defining the basic elements and specific contents of each practical ability level according to the hierarchical structure of professional practice ability. The work contents of the practical capability module mainly include:

- To define the hierarchical structure of professional practice ability.

- To define the detailed characteristics and elements of each practice capability level.

- Determine the course setting and the link between course to reflect the characteristics and elements of the practical ability levels.

2) The practical ability support module

The basic function of the practical ability support module is to provide support, resources and conditions for the realization of practical ability. The work contents of the practical ability support module mainly include:

- To establish the working process, specification, scope and content for applying the teaching resources outside and on campus. 


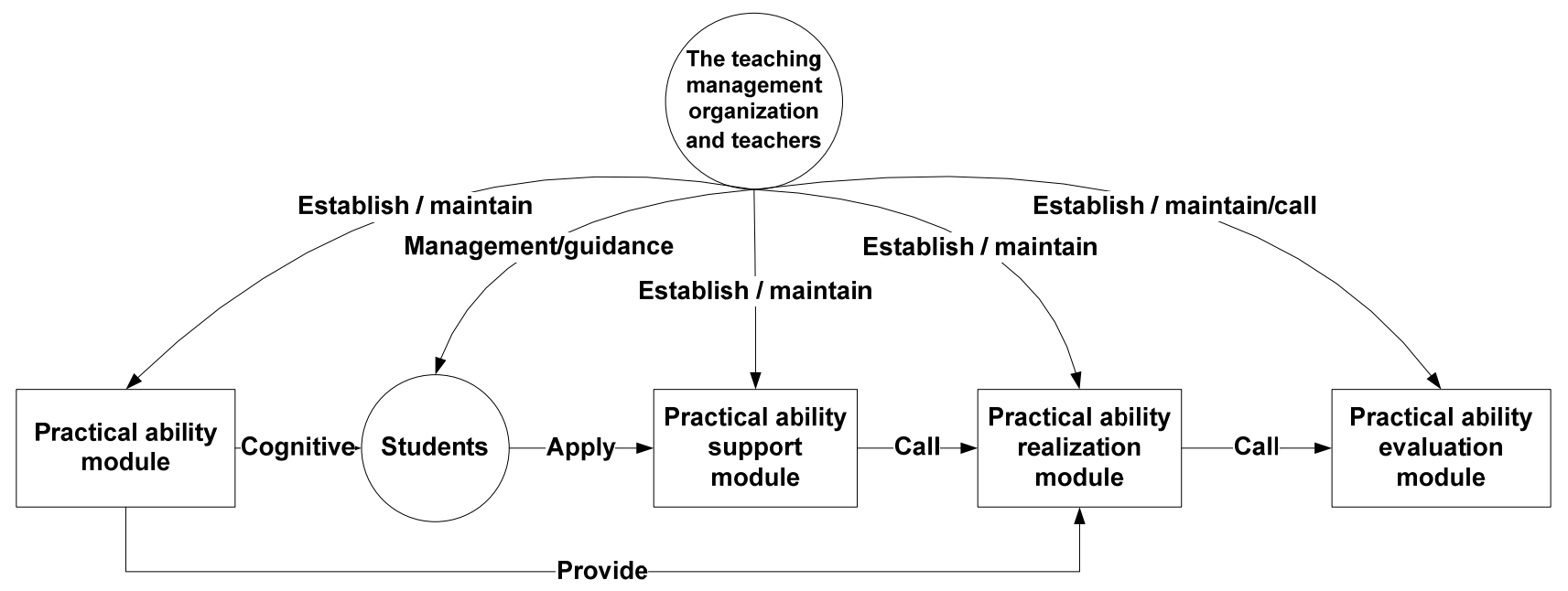

Fig. 2. The framework of the IOT engineering PTS

- To establish the working process, specification and scope of teaching resources planning and construction on campus.

- To design the agreement and utilization mechanism of software and hardware resources of outside practice teaching.

3) The practical ability realization module

The basic functions of the practical ability realization module include: defining the process and form of realizing practical ability, and optimizing the process and practice project. The work contents of the practical ability realization module mainly include:

- To determine the workflow, specifications and scope for the process, form, and content of the practice.

- According to the practical ability module, to determine and optimize the link, form and content of the realization of practical ability.

- To establish the working process, specification, standard and scope of the optimization of the practice projects.

4) The practical ability evaluation module

The basic function of the practical ability evaluation module: to evaluate the various stages, the various aspects and the various projects in the process of practical ability realization, practice teaching staff performance appraisal, and to control the quality of the realization of practical ability. The work contents of the practical ability evaluation module mainly include:

- To establish the process, specification, content and standards of the evaluation of students' practical ability.

- To establish the process, norms, content and standards of practical teaching staff performance appraisal and teaching quality monitoring.

\section{IMPLEMENTATION OF OPEN PTS OF INNOVATION-ORIENTED IOT ENGINEERING}

The main work in the PTS running process includes the implementation and improvement of the practical teaching system to realize the students' practical ability, the PTS running process shown in Figure 3. First, the students enter the practical ability module in the practical teaching system to understand the characteristics, practical ability requirements and the practical teaching process of all major direction, and to make personalized major direction choice. Then, students employ the practical teaching resources that are gathered in practical ability support module to accomplish the training plan which is set up in the practical ability realization module. The practical ability evaluation module evaluates the students that have finished the training plan, and the students who meet the practical ability standard can be identified as IOT engineering talent, otherwise the students need to enter the practical ability module again $[6,7]$.

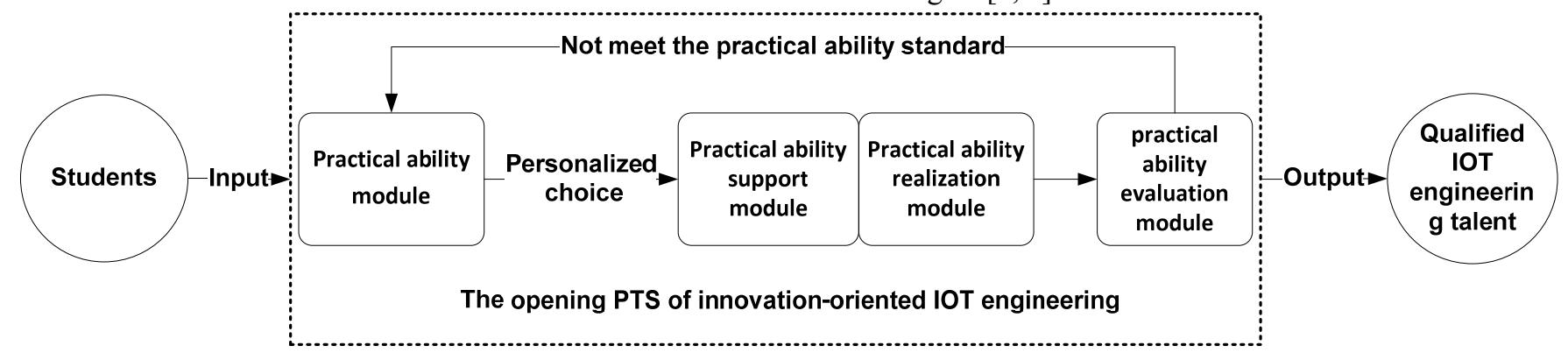

Fig. 3. The PTS running process 


\section{CONCLUSIONS}

The practical teaching system of the Internet of things is the core component of the talents training in the IOT. This paper proposes an open PTS for innovation-oriented IOT engineering to overcome the problems in the teaching system of IOT Engineering Practice. Our practice shows: First, the system can guarantee the efficient management of practice teaching; Second, students and teachers can quickly get a clear practical teaching related information; Thirdly, , students and teachers are more focused on how to improve the efficiency of realization of students' practical ability; Finally, the system can effectively meet the individual needs of students. It needs to be emphasized that this practice teaching system is a dynamic system, and it needs to adjust the corresponding modules with the changes of technical system and market demand.

\section{REFERENCES}

[1] Fang Liu. Brief Analysis of the Strategy for Transformation in and Development of Newly Upgraded Undergraduate Universities and Colleges. Journal of Educational Research. 2015, 6.

[2] Downey, G. Are Engineers Losing Control of Technology From "Problem Solving" to "Problem Definition and Solution" in Engineering Education, Chemical Engineering Research and Design, 2005, 83(2): 2129.

[3] J. Gill, R. Sharp, J. Mills and S. Franzway. I still want to be an Engineer Women, Education and the Engineering Profession. European Journal of Engineering Education, 2008, 33(4): 391-402.

[4] Steven Olson. Educating Engineers: preparing 21st Century Leaders in the Context of New Mode of Learning [R]. Summary of a Forum, the National Academy of Engineering of the National Academies, 2012.

[5] http://www.xzbu.com/8/view-7304105.htm

[6] A personalized learning resource for all ages [EB/OL]. https://www.khanacademy.org/about.

[7] Preparing the next generation of engineers. School with Approved GCS Programs. https://www.grandchallengescholars.org/activr-programs. 